\title{
A 280-GHz Self-Mixing Balanced Frequency Tripler in SiGe BiCMOS Technology
}

\author{
Turhaner, Arsen; Dong, Yunfeng; Zhurbenko, Vitaliy; Johansen, Tom Keinicke
}

Published in:

IEEE Microwave and Wireless Components Letters

Link to article, DOI:

10.1109/LMWC.2020.3019589

Publication date:

2020

Document Version

Peer reviewed version

Link back to DTU Orbit

Citation (APA):

Turhaner, A., Dong, Y., Zhurbenko, V., \& Johansen, T. K. (2020). A 280-GHz Self-Mixing Balanced Frequency Tripler in SiGe BiCMOS Technology. IEEE Microwave and Wireless Components Letters, 30(10), [9187590]. https://doi.org/10.1109/LMWC.2020.3019589

\section{General rights}

Copyright and moral rights for the publications made accessible in the public portal are retained by the authors and/or other copyright owners and it is a condition of accessing publications that users recognise and abide by the legal requirements associated with these rights.

- Users may download and print one copy of any publication from the public portal for the purpose of private study or research.

- You may not further distribute the material or use it for any profit-making activity or commercial gain

- You may freely distribute the URL identifying the publication in the public portal 


\title{
A 280-GHz Self-Mixing Balanced Frequency Tripler in SiGe BiCMOS Technology
}

\author{
Arsen Turhaner ${ }^{(}$, Yunfeng Dong ${ }^{(}$, Member, IEEE, Vitaliy Zhurbenko ${ }^{\circledR}$, Member, IEEE, \\ and Tom Keinicke Johansen, Member, IEEE
}

\begin{abstract}
In this letter, a self-mixing balanced frequency tripler is presented. It comprises a push-push frequency doubling stage followed by a single balanced mixing stage sharing the input power via coupled lines. The chip is fabricated using the SG13G2 (130-nm SiGe BiCMOS) technology of Innovations for High Performance Microelectronics (IHP). A measured output power of $3 \mathrm{dBm}$ is achieved at $280 \mathrm{GHz}$ with a dc-to-RF efficiency of $2.19 \%$.
\end{abstract}

Index Terms-Frequency tripler, mm-wave circuits, $\mathrm{SiGe} \mathrm{BiC}$ MOS, subharmonic mixer.

\section{INTRODUCTION}

$\mathbf{O}$ VER the past few years, research on the exploitation of the terahertz gap $(0.1-10 \mathrm{THz})$ for emerging applications such as short-range wideband communication, high-resolution radar and imaging, spectroscopy and material characterization has gained momentum. The inherent challenge on designing an on-chip source operating in the terahertz gap is to produce enough power as the transistor sizes are continuously scaled down to increase $f_{\mathrm{T}}$ and $f_{\max }$. Therefore, especially for sources operating above $200 \mathrm{GHz}$, frequency multiplication stages are inevitable [1]. Thus, most of the reported systems operating in the terahertz gap exploit frequency multiplication [2]-[5].

In this letter, a $280 \mathrm{GHz}$ frequency tripler is introduced. It is intended to be used in a signal source of an imaging system similar to the one described in [6], which provides $-13 \mathrm{dBm}$ of output power at $490-645 \mathrm{GHz}$. Therefore, a frequency doubler with a mediocre conversion loss below $16 \mathrm{~dB}$ placed after the proposed tripler is sufficient to reach a similar performance. The proposed tripler comprises a pushpush frequency doubling stage and a mixing stage similar to those in [7]-[9]. It operates at a much higher frequency, hence, the power distribution also becomes an issue which is handled by coupled lines. The advantage of using the selfmixing design approach compared to the traditional frequency triplers as demonstrated in [10] is that it relies on the strength

Manuscript received June 20, 2020; revised August 7, 2020; accepted August 23, 2020. The work is supported by the European Union's Horizon 2020 Research and Innovation Programme through the Convergence of Electronics and Photonics Technologies for Enabling Terahertz Applications (CELTA) Project under grant agreement no. 675683. (Corresponding author: Arsen Turhaner.)

The authors are with the Department of Electrical Engineering, Technical University of Denmark, 2800 Kongens Lyngby, Denmark (e-mail: aturh@elektro.dtu.dk; yundon@elektro.dtu.dk; vz@elektro.dtu.dk; tkj@elektro.dtu.dk).

Color versions of one or more of the figures in this letter are available online at http://ieeexplore.iee.org.

Digital Object Identifier 10.1109/LMWC.2020.3019589

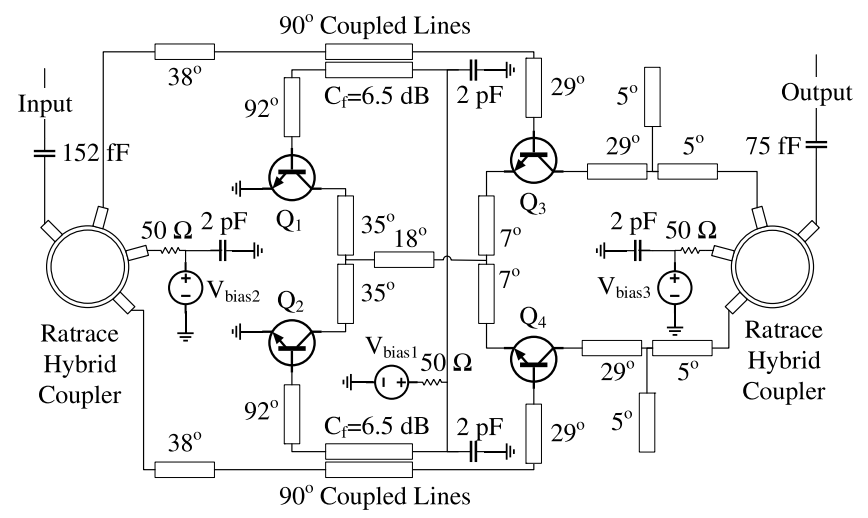

Fig. 1. Full schematic of the frequency tripler. The characteristic impedance of the transmission lines is $50 \Omega$ and the electrical lengths are given at $93.3 \mathrm{GHz}$

of the first- and the second-order nonlinearities instead of the third-order nonlinearity.

The letter is organized as follows. In Section II, the circuit design is presented. In Section III, the simulation and the measurement results are given along with the discussion. Finally, Section IV concludes the letter.

\section{Circuit Design}

The circuit topology is shown in Fig. 1. Transistors $\mathrm{Q}_{1}$ and $\mathrm{Q}_{2}$ belong to the push-push frequency doubling stage whereas $\mathrm{Q}_{3}$ and $\mathrm{Q}_{4}$ perform single balanced mixing. Coupled lines are used to divide the input power between these two stages. For a differential system, the ratrace hybrid couplers are not needed and the topology can be very compact.

In the proposed design, all the transistors have ten emitter fingers to increase the current driving capability. Base bias voltage is chosen for the frequency doubling stage to have a reduced angle of conduction. This boosts the second harmonic generation. The signal from the thru ports of the coupled lines must be powerful enough to commutate the current flowing in the mixing stage transistors. The elements of the matching networks are optimized considering the output power and the routing in the layout.

\section{A. Balun Design}

The balun has to have a low loss at the frequency of operation in order to reduce the RF input power level requirement and preserve the output power. Considering the design frequency, two balun structures become prominent: 1) ratrace hybrid coupler and 2) Marchand balun. Electromagnetic (EM) simulations of both structures are compared 


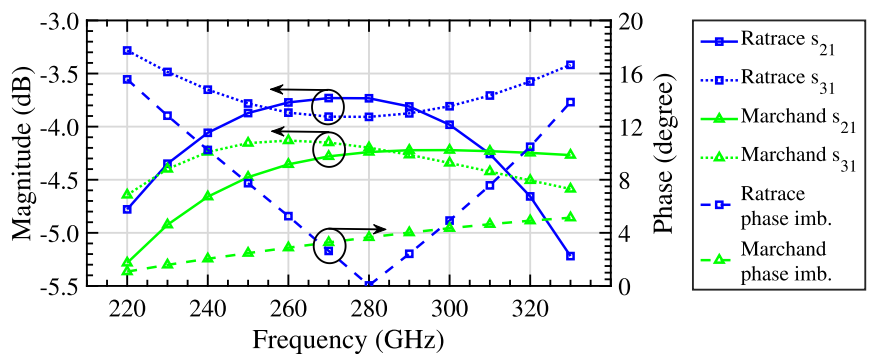

Fig. 2. Insertion loss and phase imbalance.

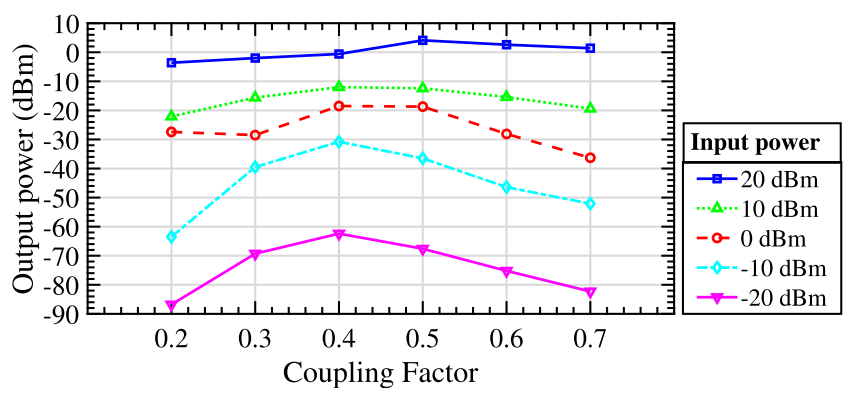

Fig. 3. Simulated output power versus the coupling factor.

across 220-330 GHz using Keysight Advanced Design System (ADS) on optimized layouts based on the layer stack of the SG13G2 technology.

The simulation results for the balun structures are given in Fig. 2. For the ratrace hybrid coupler, it can be deduced that the loss is less than $1 \mathrm{~dB}$ for a $20 \%$ bandwidth at around $270 \mathrm{GHz}$. The amplitude imbalance is less than $1 \mathrm{~dB}$ for a $30 \%$ bandwidth at around $270 \mathrm{GHz}$. The phase imbalance is quite low around the targeted center frequency of the design. For the Marchand balun, the loss is higher, however, the amplitude and the phase imbalances are quite low. The EM simulation results show that both structures are well matched for the full band with a return loss of more than 15 and $10 \mathrm{~dB}$ for the ratrace hybrid coupler and the Marchand balun, respectively. The output ports, however, are matched in the ratrace hybrid coupler but not in the Marchand balun. The ratrace hybrid coupler is chosen because of its low loss, good match, and sufficiently low imbalance in the frequency band of interest.

\section{B. Optimization of the Third Harmonic Generation}

Assuming the RF signal driving the mixing stage is powerful enough to commutate the collector current, the third harmonic component of the output current depends on the dc bias and the RF signal introduced to the base of the frequency doubling stage transistors, and the phase difference, $\phi$, between the signals reaching the base of the frequency doubling stage transistors and the mixing stage transistors. If the electrical lengths of the interstage matching network are neglected, it can be shown that the output power is maximized when $\phi=(2 k+$ 1) $\cdot 90^{\circ}$, where $k$ is an integer. The transmission line lengths are chosen to provide a phase difference of $270^{\circ}$ at $93.3 \mathrm{GHz}$ taking into account the parasitics of via interconnects and the capacitive loading of the input of the transistors.

Another important parameter is the coupling factor which affects the power division between the stages. Enhancing the coupling factor and hence, increasing the RF input power introduced to the frequency doubling stage, improves the output power as long as there is enough power to drive the

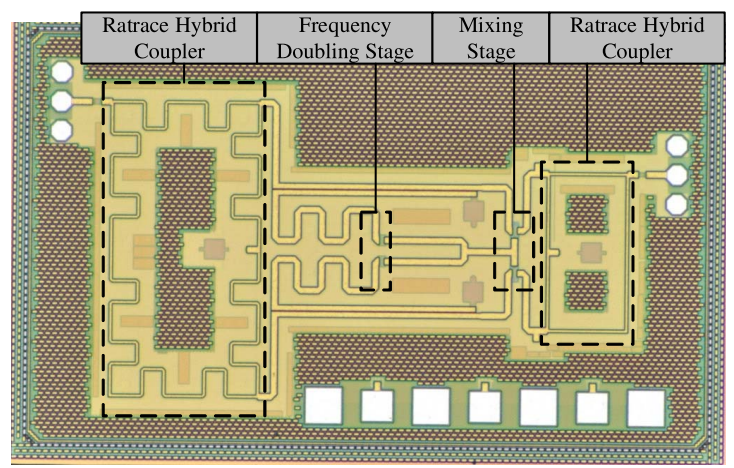

Fig. 4. Chip photograph of the frequency tripler with the indicated building blocks. The chip size is $0.8 \times 1.3 \mathrm{~mm}^{2}$.

mixing stage. This relation can also be seen in Fig. 3. For the figure, the base bias voltages are optimized for a coupling factor of 0.45 and otherwise kept fixed. As is seen, as the input power increases, a higher coupling factor is favored.

\section{Measurement Results}

The fabricated chip is measured on-wafer using $50-\mu \mathrm{m}$ pitch Picoprobes from GGB Industries in a ground-signal-ground (GSG) configuration. In order to generate the input signal, a customized source is used with an adjustable attenuator. This is a narrowband source $(92-96 \mathrm{GHz})$ with a high output power [11]. For the full band measurements, an AFM6-110, $\times 6$ frequency multiplier, and a W-MPA power amplifier both from Radiometer Physics $\mathrm{GmbH}$ are driven from an Anritsu MG3694A signal generator. The W-MPA has a lower output power than the customized source has. On the receiver side, a PM5 Erickson power meter from Virginia Diodes, Inc., (VDI) is used. In order to verify the results and measure the suppression of the unwanted harmonics, measurements are repeated using harmonic mixers (11970W model from Keysight, M05HWD and M03HWD models from OML with DPL26 diplexer). The sources are calibrated using the power meter. Sufficient time is allowed for the power meter to settle for each measurement. For the full band measurement, the source with the $\times 6$ frequency multiplier and the W-MPA is also calibrated using the $11970 \mathrm{~W}$ harmonic mixer for verification. The photograph of the chip is shown in Fig. 4 . The chip size is $0.8 \times 1.3 \mathrm{~mm}^{2}$.

The first experiment is to characterize the behavior of the output power at the center frequency of $280 \mathrm{GHz}$ with respect to $V_{\text {bias1 }}$ (refer to Fig. 1). For this purpose, the narrowband customized source is used [11]. The $V_{\text {bias2 }}$ is optimized for each measurement and the collector voltage is kept constant at $3.2 \mathrm{~V}$. The results of the characterization is given in Fig. 5 in which the input power level is incrementally increased. The collector current depends on the RF input power level and the $V_{\text {bias1 }}$. When the $V_{\text {bias } 1}$ is less than $0.5 \mathrm{~V}$ with an $\mathrm{RF}$ input power of less than $13 \mathrm{dBm}$, the dc current is below $1 \mathrm{~mA}$. It increases to approximately $15 \mathrm{~mA}$ when more than $15 \mathrm{dBm}$ of RF input power is used with a dc bias of more than $0.75 \mathrm{~V}$. It can be concluded from Fig. 5 that for the low input power, the curves have a class B operation characteristic, and as the input power increases, they show the characteristic of an over-driven class A operation for the frequency doubling stage. In this highly nonlinear mode of operation, the output power is boosted by the harmonic generation. 


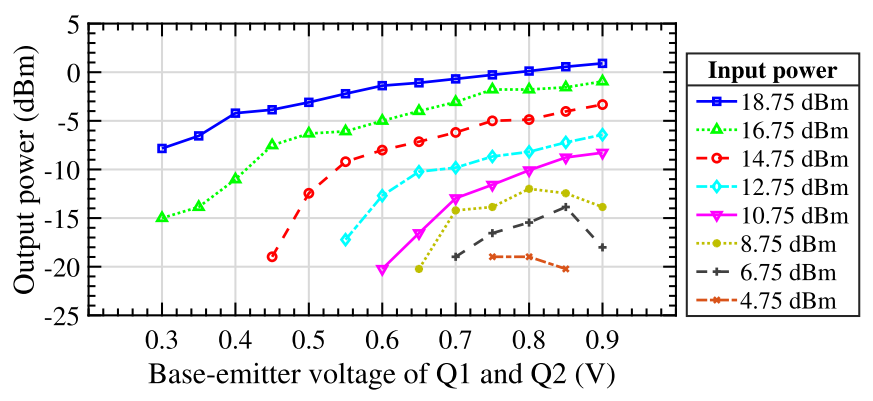

Fig. 5. Measured output power versus the base-emitter voltage of the transistors $\mathrm{Q}_{1}$ and $\mathrm{Q}_{2}$ for incrementally increased input power levels.

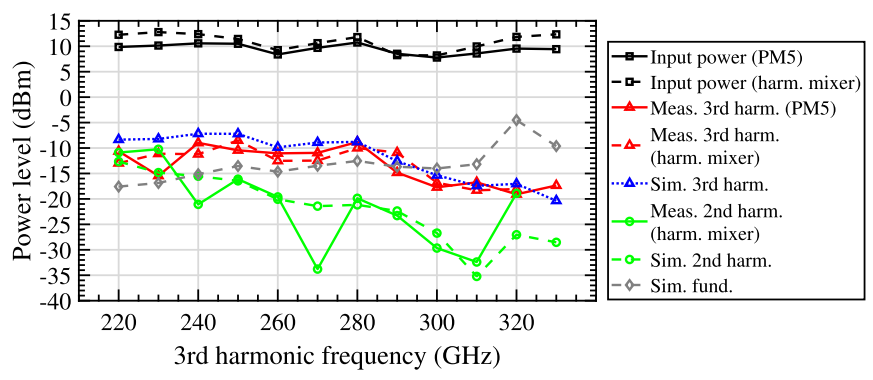

Fig. 6. Full band measurement of the output power and its comparison to the simulation results.

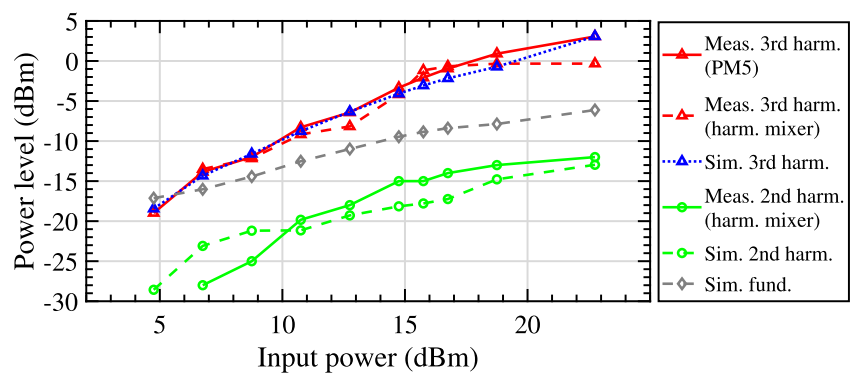

Fig. 7. Measured output power and its comparison to the simulation results at $280 \mathrm{GHz}$.

The second experiment is to characterize the behavior of the output power for the full band $(220-330 \mathrm{GHz})$. For this purpose, the source with the $\times 6$ frequency multiplier and the W-MPA is used. Base biases are adjusted to maximize the output power at each frequency. The collector voltage is kept constant at $3.2 \mathrm{~V}$. The results are given in Fig. 6. The PM5 data agrees well with the harmonic mixer data. In general, a good agreement between the simulations and measurements is observed. Discrepancies between the measured second harmonic and the simulation are probably due to having a mismatch at the second and the third harmonics during the measurements with the M05HWD harmonic mixer and a $140-220 \mathrm{GHz}$ probe. Minimum $10 \mathrm{~dB}$ of a second harmonic suppression is obtained around the frequency of interest. Due to the lack of a second $W$-band probe, the fundamental signal suppression could not be measured, therefore, simulation results are given instead. As the fundamental signal is also a product of mixing, it appears in the spectrum. However, it is far away from the third harmonic; thus, it can be easily suppressed by an external filter. In addition, as the input power increases, the fundamental signal suppression improves as it is seen in the following experiment.

The third experiment is conducted to obtain the saturated output power at $280 \mathrm{GHz}$. The results are given in Fig. 7.
TABLE I

PERformance COMParison to THE STATE-OF-THE-ART

\begin{tabular}{|c|c|c|c|c|c|c|c|}
\hline Technology & $\begin{array}{l}\text { Freq. } \\
(\mathrm{GHz})\end{array}$ & Topology & $\begin{array}{c}P_{\text {out,peak }} \\
(\mathrm{dBm})\end{array}$ & \begin{tabular}{|c|}
$P_{D C}$ \\
$(\mathrm{~mW})$ \\
\end{tabular} & $\eta_{\mathrm{dc}}{ }^{*}$ & \begin{tabular}{|c|}
$P_{\text {in }}$ \\
$(\mathrm{dBm})$ \\
\end{tabular} & Ref \# \\
\hline $\begin{array}{l}30 \mathrm{~nm} \mathrm{SiGe} \\
\text { BiCMOS }\end{array}$ & 325 & Amp. + Doubler & -3 & 420 & $0.12 \%$ & -7 & {$[12]$} \\
\hline $\begin{array}{c}130 \mathrm{~nm} \mathrm{SiGe} \\
\text { BiCMOS }\end{array}$ & 220 & Amp. + Doubler & -1 & 630 & $0.13 \%$ & 0 & {$[12]$} \\
\hline $\begin{array}{c}90 \mathrm{~nm} \text { SiGe } \\
\text { BiCMOS }\end{array}$ & 215 & $\begin{array}{l}\text { Amp. + 4-Way } \\
\text { Comb. Doublers }\end{array}$ & 8 & 2700 & $0.23 \%$ & 12.7 & {$[13$} \\
\hline $\begin{array}{c}130 \mathrm{~nm} \mathrm{SiGe} \\
\text { BiCMOS }\end{array}$ & 204 & 2-Way PA + Doubler & 6.5 & 394 & $1.13 \%$ & 2 & {$[14]$} \\
\hline $\begin{array}{c}55 \mathrm{~nm} \mathrm{SiGe} \\
\text { BiCMOS }\end{array}$ & 240 & $\begin{array}{c}\text { VCO + Amp. }+ \\
\text { Doubler w/Divider }\end{array}$ & 7.2 & 386 & $1.36 \%$ & - & {$[15]$} \\
\hline $\begin{array}{c}130 \mathrm{~nm} \mathrm{SiGe} \\
\mathrm{BiCMOS}\end{array}$ & 284 & 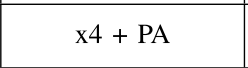 & 2.5 & 384 & $46 \%$ & 0 & {$[16$} \\
\hline $\begin{array}{c}130 \mathrm{~nm} \mathrm{SiGe} \\
\mathrm{BiCMOS}\end{array}$ & 270 & Amp. + Doubler & -0.5 & 429 & $0.21 \%$ & -14 & {$[17$} \\
\hline $\begin{array}{c}130 \mathrm{~nm} \mathrm{SiGe} \\
\mathrm{BiCMOS}\end{array}$ & 235 & $\begin{array}{c}\mathrm{x} 8+\text { Amp. }+ \\
\text { 4-Way PA }\end{array}$ & $13.5^{* *}$ & 990 & $2.30 \%^{* *}$ & -6 & {$[18]$} \\
\hline $\begin{array}{c}130 \mathrm{~nm} \mathrm{SiGe} \\
\text { BiCMOS }\end{array}$ & 280 & Tripler & 3 & 91.2 & $2.19 \%$ & 22.75 & \begin{tabular}{|c|} 
This \\
work
\end{tabular} \\
\hline
\end{tabular}

* dc-to-RF efficiency as defined in [10]

** With de-embedding input and output baluns and pads

For this measurement, the narrowband customized source is used again [11]. Base biases are adjusted to maximize the third harmonic power at each input power level. The results are not compensated for any ratrace hybrid coupler and RF pad loss. The graph shows good agreement between the simulation and the PM5 measurement of the third harmonic output power. The harmonic mixer data also agrees well with the PM5 data for the input power levels of less than $17 \mathrm{dBm}$. Due to the lack of an attenuator at $280 \mathrm{GHz}$, the harmonic mixer goes into compression and does not give reliable results in the range of highest output powers. The output power of $3 \mathrm{dBm}$ is achieved with a dc power consumption of only $91.2 \mathrm{~mW}$ measured under continuous wave $(\mathrm{CW})$ operation. This translates into a dc-to-RF efficiency of $2.19 \%$. In order to reach this value, the collector voltage is pushed up to $3.8 \mathrm{~V}$ with a collector current of $24 \mathrm{~mA}$. It is also seen in Fig. 7 that the fundamental signal suppression and the second harmonic suppression of 9 and $15 \mathrm{~dB}$ are achieved, respectively, when sufficient input power is used.

The comparison of this work to the state-of-the-art for SiGe BiCMOS based designs from the literature is given in Table I. This work has the simplest topology, and hence, the lowest dc power consumption, and one of the highest dc-to-RF efficiencies. In addition, the measured peak power of $3 \mathrm{dBm}$ is competitive considering the frequency of operation. The required input power is high, but this is due to being a topology demonstration without any preamplification.

\section{CONCLusion}

A frequency tripler with a novel topology is demonstrated. The measured output power of $3 \mathrm{dBm}$ is the state-of-theart at this frequency for active SiGe BiCMOS-based on-chip sources. The topology enables a differential design with a compact layout and achieves a high dc-to-RF efficiency.

\section{ACKNOWLEDGMENT}

The authors would like to thank Peter Bodin from the Department of Health Technology and Pengyu Guan from the Department of Photonics Engineering at Technical University of Denmark (DTU) for the support. 


\section{REFERENCES}

[1] N. Sarmah, B. Heinemann, and U. R. Pfeiffer, "235-275 GHz (x16) frequency multiplier chains with up to $0 \mathrm{dBm}$ peak output power and low DC power consumption," in Proc. IEEE Radio Freq. Integr. Circuits Symp., Jun. 2014, pp. 181-184.

[2] B. P. Ginsburg, S. M. Ramaswamy, V. Rentala, E. Seok, S. Sankaran, and B. Haroun, "A $160 \mathrm{GHz}$ pulsed radar transceiver in $65 \mathrm{~nm}$ CMOS," IEEE J. Solid-State Circuits, vol. 49, no. 4, pp. 984-995, Apr. 2014.

[3] T. Jaeschke, C. Bredendiek, and N. Pohl, "A $240 \mathrm{GHz}$ ultra-wideband FMCW radar system with on-chip antennas for high resolution radar imaging," in IEEE MTT-S Int. Microw. Symp. Dig, Jun. 2013, pp. 1-4.

[4] E. Ojefors, J. Grzyb, Y. Zhao, B. Heinemann, B. Tillack, and U. R. Pfeiffer, "A $820 \mathrm{GHz}$ SiGe chipset for terahertz active imaging applications," in Proc. IEEE Int. Solid-State Circuits Conf., Feb. 2011, pp. 224-226.

[5] N. Sarmah, P. R. Vazquez, J. Grzyb, W. Foerster, B. Heinemann, and U. R. Pfeiffer, "A wideband fully integrated SiGe chipset for high data rate communication at $240 \mathrm{GHz}$," in Proc. 11th Eur. Microw. Integr. Circuits Conf. (EuMIC), Oct. 2016, pp. 181-184.

[6] M. Bauer et al., "A high-sensitivity AlGaN/GaN HEMT terahertz detector with integrated broadband bow-tie antenna," IEEE Trans. THz Sci. Technol., vol. 9, no. 4, pp. 430-444, Jul. 2019.

[7] B. R. Jackson, F. Mazzilli, and C. E. Saavedra, "A frequency tripler using a subharmonic mixer and fundamental cancellation," IEEE Trans. Microw. Theory Techn., vol. 57, no. 5, pp. 1083-1090, May 2009.

[8] Y. Lo and J. Kiang, "A $0.18 \mu \mathrm{m}$ CMOS self-mixing frequency tripler," IEEE Microw. Wireless Compon. Lett., vol. 22, no. 2, pp. 79-81, 2012.

[9] S. Saberi Ghouchani and J. Paramesh, "A wideband millimeter-wave frequency doubler-tripler in 0.13- $\mu \mathrm{m}$ CMOS," in Proc. IEEE Radio Freq. Integr. Circuits Symp., May 2010, pp. 65-68.
[10] S. A. Maas, Nonlinear Microwave and RF Circuits, 2nd ed. Norwood, MA, USA: Artech House, 2003, ch. 10, pp. 475-495.

[11] J. Ardenkjær-Larsen et al., "Cryogen-free dissolution dynamic nuclear polarization polarizer operating at $3.35 \mathrm{~T}, 6.70 \mathrm{~T}$, and $10.1 \mathrm{~T}$," Magn. Reson. Med., vol. 81, no. 3, pp. 2184-2194, Mar. 2019.

[12] E. Öjefors, B. Heinemann, and U. R. Pfeiffer, "Active 220- and 325-GHz frequency multiplier chains in an SiGe HBT technology," IEEE Trans. Microw. Theory Techn., vol. 59, no. 5, pp. 1311-1318, May 2011.

[13] H. Lin and G. M. Rebeiz, "A SiGe multiplier array with output power of 5-8 dBm at 200-230 GHz," IEEE Trans. Microw. Theory Techn., vol. 64, no. 7, pp. 2050-2058, Jul. 2016.

[14] K. Wu, S. Muralidharan, and M. M. Hella, "A wideband SiGe BiCMOS frequency doubler with $6.5-\mathrm{dBm}$ peak output power for millimeter-wave signal sources," IEEE Trans. Microw. Theory Techn., vol. 66, no. 1, pp. 187-200, Jan. 2018.

[15] S. Shopov, A. Balteanu, J. Hasch, P. Chevalier, A. Cathelin, and S. P. Voinigescu, "A 234-261-GHz 55-nm SiGe BiCMOS signal source with 5.4-7.2 dBm output power, 1.3\% DC-to-RF efficiency, and 1-GHz divided-down output," IEEE J. Solid-State Circuits, vol. 51, no. 9, pp. 2054-2065, Sep. 2016.

[16] P. Zhou, J. Chen, P. Yan, Z. Chen, D. Hou, and W. Hong, "A 280-325 $\mathrm{GHz}$ frequency multiplier chain with $2.5 \mathrm{dBm}$ peak output power," in Proc. IEEE Custom Integr. Circuits Conf. (CICC), Apr. 2019, pp. 1-4.

[17] F. Ahmed, M. Furqan, and A. Stelzer, "A 0.3-THz SiGe-based frequency doubler chip with 3-dB $50 \mathrm{GHz}$ bandwidth and $17 \mathrm{~dB}$ peak conversion gain," in Proc. 12th Eur. Microw. Integr. Circuits Conf. (EuMIC), Oct. 2017, pp. 134-137.

[18] M. H. Eissa, A. Malignaggi, and D. Kissinger, "A 13.5-dBm 200$255-\mathrm{GHz}$ 4-way power amplifier and frequency source in 130-nm BiCMOS," IEEE Solid-State Circuits Lett., vol. 2, no. 11, pp. 268-271, Nov. 2019. 